\title{
Legitimacy and Cooperation: Why Do People Help the Police Fight Crime in Their Communities? ${ }^{\dagger}$
}

\author{
Tom R. Tyler* and Jeffrey Fagan**
}

Past research indicates that legitimacy encourages compliance with the law. This study extends consideration of the influence of legitimacy by exploring its impact on cooperation with the police and with neighbors to combat crime in one's community. It uses a panel study design and focuses upon the residents of New York City. The study finds that legitimacy shapes cooperation with the police and has a lesser influence on cooperation with others in the community. Consistent with the findings of prior research, legitimacy itself is found to be linked to the justice of the procedures used by the police to exercise their authority. Finally, the study explores the influence of personal experience with the police on legitimacy and cooperation. Results suggest that experiencing procedural justice during a personal experience increases legitimacy, irrespective of the favorability of the outcome. These results suggest that the police can generally enhance their legitimacy by using fair procedures.

$\uparrow$ Generous support for this research was provided by Grant 98-VF-GX-0005 from the National Institute of Justice and Grant SES-0240938 from the National Science Foundation. All opinions are those of the authors and do not reflect the views or positions of the Department of Justice or the National Science Foundation. Vivian Wang provided excellent research assistance.

- University Professor, Department of Psychology and School of Law, New York University.

* Professor of Law and Public Health, Columbia University; Director, Center on Crime, Community and Law, Columbia Law School. 


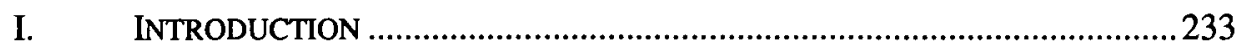

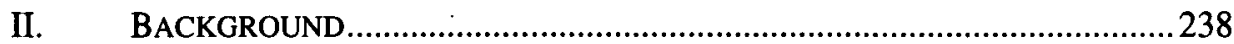

A. Why Are the Police Legitimate? ....................................................238

B. The Influence of Personal Experience with the Police ..................240

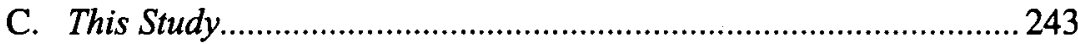

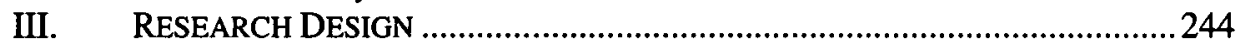

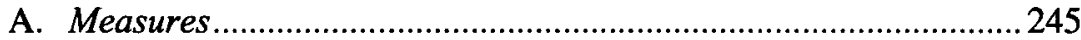

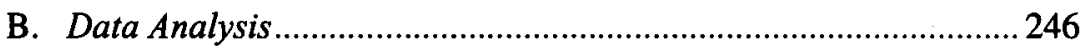

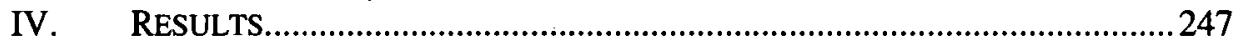

A. Is Cooperation Distinct from Compliance? ................................... 247

B. Why Do People Cooperate with the Police and with Others in Their Communities?............................................................... 250

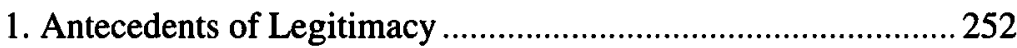

2. Personal Experience with the Police............................................255

C. Must Regulation Undermine Legitimacy? .....................................256

V. DiSCUSSION .....................................................................................262

A. Why Do People Cooperate with the Police?................................. 262

B. How Is Legitimacy Created and Maintained?: The Role of Procedural Justice ..................................................................... 264

C. Strengths and Weaknesses of This Study .....................................265

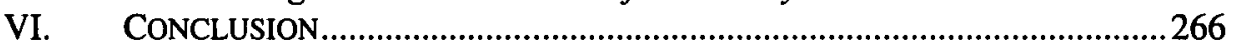




\section{INTRODUCTION}

To be effective in lowering crime and creating secure communities, the police must be able to elicit cooperation from community residents. Security cannot be produced by either the police or community residents acting alone-it requires cooperation. Such cooperation potentially involves, on the part of the public, both obeying the law ${ }^{1}$ and working with the police or others in the community to help combat crime in the community. ${ }^{2}$

How can cooperation be motivated, and, conversely, what factors defeat cooperation and for whom? To answer these questions, we contrast two models of cooperation. The first is a social control or instrumental model, which argues that people are motivated by self-interest. ${ }^{3}$ The second is a legitimacy or social norms model, which hypothesizes that people's views about the institutional legitimacy of the police and the law also influence their cooperation.

The social control or instrumental perspective argues that people's actions are governed by their self-interest either in the form of sanctions or incentives. ${ }^{4}$ Consistent with rational choice assumptions about human motivation, the police can encourage cooperative behavior by giving cooperation greater personal utility for community residents, for example by demonstrating that the police are effective in fighting crime ${ }^{5}$ and/or that rule breakers are punished. ${ }^{6}$ Shared beliefs among neighborhood residents that their community works collectively to address

I See generally TOM R. TYLER, WHY PEOPLE OBEY THE LAW (2006) [hereinafter TYLER, WhY PEOPLE OBEY] (discussing instrumental and normative perspectives on why people follow the law).

2 See, e.g., Robert J. Sampson, Stephen W. Raudenbush \& Felton Earls, Neighborhoods and Violent Crime: A Multilevel Study of Collective Efficacy, 277 SCIENCE 918, 918, 923 (1997) (finding, in study of Chicago neighborhoods, that informal social control among neighbors is linked with lower rates of violence).

3 Although our conceptual framework is compatible with economics perspectives on citizen interactions with criminal legal institutions and on crime, we avoid an explicit model of reward and sanction resulting from contacts with legal actors. We do claim that the costs of adverse interactions with police and poor outcomes are reduced incentives to cooperate with police and to comply with legal norms. See A. Mitchell Polinsky \& Steven Shavell, The Theory of Public Enforcement of Law, in 1 HANDBOOK Of LAW AND ECONOMICS (2007); see also Oren Bar-Gill \& Alon Harel, Crime Rates and Expected Sanctions: The Economics of Deterrence Revisited, 30 J. LEGAL STUD. 485 (2001).

4 See Daniel S. Nagin, Criminal Deterrence Research at the Outset of the Twenty-First Century, 23 CRIME \& JUST. 1, 7 (1998) (discussing research that "points overwhelmingly to the conclusion that behavior is influenced by sanction risk perceptions-those who perceive that sanctions are more certain or severe are less likely to commit crime").

5 George L. Kelling \& Catherine M. Coles, Fixing Broken Windows 102-07 (1996) (advocating shift from "reactive, 911 policing and return to a model of policing" that emphasizes crime prevention and order maintenance).

6 See, e.g., Nagin, supra note 4, at 34-35 (arguing that credibility of sanction policies depends in part on police and prosecutor resources and on sentencing and release decisions of judges and parole boards); see also DAVID H. BAYleY \& HAROLD MENDELSOHN, MiNORITIES AND THE POLICE 58-86 (1968) (discussing Denver study indicating that racial minorities may be less willing to contact police for assistance because of perceptions of police attitude toward them). 
local problems have, for example, been shown to motivate community residents to work with each other to fight crime and disorder in their communities. ${ }^{7}$ Prior studies of policing have used several approaches to assess instrumental aspects of policing, including estimates of the rate of crime, fear of crime and police effectiveness in sanctioning criminal behavior. ${ }^{8}$

Unfortunately, from the instrumental perspective, it is in some people's shortterm self-interest to break, rather than to obey, the law. ${ }^{9}$ Cooperation with law enforcement agencies and other legal actors follows suit. That is, some people may see little immediate personal utility in supporting police efforts to control crime, reporting crimes and criminals, or helping in community efforts to fight crime. In addition, helping has short term costs. Those costs could potentially be minor inconveniences but could also involve serious danger of retaliation. Hence, strategies appealing to self-interest are often an inadequate basis for managing crime and security. Empirical research supports this argument by finding only weak correlations between risk and compliance, ${ }^{10}$ as well as little connection between police performance and public cooperation with the police. ${ }^{11}$

How else, then, can the police obtain public cooperation? Past research suggests that most people also obey the law because they view it as legitimate. ${ }^{12}$ That is, law expresses moral and social norms that are widely held by both

7 Sampson et al., supra note 2, at 919 ("IS]ocially cohesive neighborhoods will prove the most fertile contexts for the realization of informal social control. . . [T] residents is a critical means by which urban neighborhoods inhibit the occurrence of personal violence ...."). Conversely, weak social ties among neighborhood residents contribute to a rejection of legal norms and their underlying moral dimensions. See Robert J. Sampson \& Dawn Jeglum Bartusch, Legal Cynicism and (Subcultural?) Tolerance of Deviance: The Neighborhood Context of Racial Differences, 32 LAW \& SOC'Y REV. 777, 783, 800-01 (1998) (suggesting that perceived normlessness is greater in "inner-city contexts of racial segregation and concentrated disadvantage, where inability to influence the structures of power . . . breed[s] cynicism and perceptions of legal injustice"); David S. Kirk \& Andrew V. Papachristos, Legal Cynicism and the Framing of Neighborhood Violence: Implications For 'Neighborhood Effects' Research (Dec. 28, 2007) (unpublished manuscript), available at http://ssrn.com/abstract=1081894 (discussing link between "legal cynicism" and neighborhood rates of violence).

8 See Nat'l Res. Council, Fairness and Effectiveness in Policing 22-27 (Wesley Skogan \& Kathleen Frydl eds., 2004) [hereinafter FAIRNESS AND EFFECTIVENESS IN POLICING].

9 TYleR, Why PEOPLE OBEY, supra note 1, at 4, 20-21 (presenting instrumental perspective of compliance where individuals' compliance with law depends on likelihood of punishment).

10 See Robert J. MacCoun, Drugs and the Law: A Psychological Analysis of Drug Prohibition, 113 PSYCHOL. BULL. 497, 499-501 (1993) (discussing limited deterrence effect, in context of illicit drug use, stemming from limited public knowledge of criminal law system and weak correlation between perceived severity of sanction and criminal conduct).

11 See Jason Sunshine \& Tom R. Tyler, The Role of Procedural Justice and Legitimacy in Shaping Public Support for Policing, 37 LAw \& SoC'Y REv. 513, 519-21 (2003) (suggesting that police treatment of people in the community has a stronger effect on legitimacy than quality of police performance).

12 See Tyler, Why PEOPLE OBEy, supra note 1, at 170-78 (suggesting psychology of legitimacy wherein people obey authorities and institutions that they trust). 
dominant and subordinate social groups. ${ }^{13}$ Accordingly, the legitimacy argument suggests that the police can gain leverage for the co-production of security by inculcating the popular perception that their actions and decisions are legitimate. This argument builds upon a long line of theory that argues for the centrality of legitimacy to the effectiveness of state actors. ${ }^{14}$

What is legitimacy? Legitimacy is a feeling of obligation to obey the law and to defer to the decisions made by legal authorities. ${ }^{15}$ Legitimacy, therefore, reflects an important social value, distinct from self-interest, to which social authorities can appeal to gain public deference and cooperation. ${ }^{16}$ In past research, legitimacy has been measured using items reflecting the perceived obligation to obey legal

13 See generally DAVID BeETHAM, The Legitimation of POWER 15-17 (1991) (defining legitimacy along three dimensions, including rules that are "justified in terms of beliefs shared by both dominant and subordinate"); Tom R. Tyler, Psychological Perspectives on Legitimacy and Legitimation, 57 ANN. REv. PSYCHOL. 375 (2006) [hereinafter Tyler, Psychological Perspectives] (discussing ways in which legitimacy facilitates state exercise of power because individuals view authorities as morally or normatively appropriate).

14 BeETHAM, supra note 13 , at 117-60, 118 (arguing that the "contemporary state . . requires legitimation ... to maintain its political system intact in the face of serious policy failure or challenge ...."). See also 1 MAX WeBER, ECONOMY AND SOCIETY 212-16 (Guenther Roth \& Claus Wittich eds., Ephraim Fischoff et al. trans., 1968) (discussing legitimation of state power based on individuals' acceptance of and submission to that power and arguing for the value to the state of being viewed as legitimate among the populace).

15 BEETHAM, supra note 13, at 18 ("[L]egitimacy involves the demonstrable expression of consent on the part of the subordinate to the particular power relation in which they are involved, through actions which provide evidence of consent."); see TYLER, WHY PEOPLE OBEY, supra note 1, at 25 (stating that "legitimacy exists when the members of a society see adequate reason for feeling that they should voluntarily obey the commands of authorities"); Tyler, Psychological Perspectives, supra note 13, at 378 ("One aspect of values-obligation-is a key element in the concept of legitimacy. It leads to voluntary deference to the directives of legitimate authorities and rules."). But see 3 WEBER, supra note 14, at 941-54.

16 John R. P. French, Jr. \& Bertram Raven, The Bases of Social Power, in STUdIES IN SocLaL POWER 150, 158-62 (Dorwin Cartwright ed., 1959) (defining legitimacy as rooted in internalized values, such as expertise or social class, through which individuals feel obligated to accept the authority's power); Herbert C. Kelman \& V. LeE Hamilton, Crimes of ObedienCE: TOWARd a SOCIAL PSYCHOLOGY OF AUTHORITY AND RESPONSIBILTY 77-102 (1989) (discussing how obedience-where people follow orders out of a sense of duty-depends on legitimacy of authority);

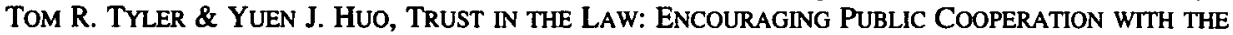
POLICE AND COURTS 7-18 (2002) (advocating a "process-based model of regulation that encourages voluntary deference" to authorities based on faimess in exercise of authority); TYLER, WHY PEOPLE OBEY, supra note 1, at 23-30 (summarizing past studies suggesting that legitimacy exists when society internalizes normative reasons for voluntarily obeying the commands of authorities). 
authorities, as well as trust and confidence in authorities. ${ }^{17}$ Recent studies have also operationalized legitimacy via identification with the police. ${ }^{18}$

While past research supports the argument that legitimacy encourages deference, more recent research emphasizes the importance of the ability of the police to leverage and secure cooperation from the public. Cooperation takes several forms, from reporting crimes to the police to assisting the police in investigations. This study tests the potential value of legitimacy in motivating these forms of public cooperation with local legal authorities. We refer to this approach as "self-regulation" because it draws upon the norms, values and preferences of community residents. When people cooperate with the police and other legal actors because of norms or values they share with the law, their behavior may be linked more to intrinsic motivations and less to the influence of sanctions or incentives on behavior. ${ }^{19}$ We hypothesize that legitimacy influences the willingness to cooperate with the police, independent of sanction risks or experiences with punishment.

Accordingly, this study assesses the contribution of legitimacy to cooperation with the police and other legal actors to fight crime and produce security. Specifically, we examine whether citizens' views about the legitimacy of the police shape two specific forms of cooperative behavior among community residents: cooperation with the police in their response to crime and working collaboratively and collectively with others in the neighborhood to maintain social order.

In exploring the influence of legitimacy, this study also distinguishes the influence of legitimacy from the influence of a second noninstrumental variableidentification with one's neighborhood. Research from social psychology demonstrates that one central reason that people cooperate generally is that they identify with their communities, linking their sense of self (identity) to the wellbeing of their group. ${ }^{20}$ Following research in this tradition, we define identification with the community as "self-group merging."21

17 Tyler, Psychological Perspectives, supra note 13, at 379-80 (reviewing studies that indicate that authorities who exercise power fairly will be viewed as legitimate and have their decisions accepted).

18 TYLER \& HUO, supra note 16, at 198-203 (advocating policing strategies that incorporate the process-based model, emphasizing fair and respectful treatment to encourage consent and cooperation).

19 Tom R. Tyler \& John M. Darley, Building a Law-Abiding Society: Taking Public Views About Morality and the Legitimacy of Legal Authorities into Account When Formulating Substantive Law, 28 HoFSTRA L. REV. 707, 714-17 (2000) (discussing legitimacy as shaping "obe[dience of] laws because [people] regard deferring to social authorities as part of the obligations associated with citizenship").

20 TOM. R. TYLER \& STEVEN L. BLADER, COOPERATION IN Groups 143-68 (2000) [hereinafter TYLER \& BLADER, COOPERATION] (observing that procedural justice affirms the relationship between people and groups by "showing that the group to which they belong is . . valuable . . . and that the group values them").

21 See id. 
This study tests two hypotheses. The first is that perceived or attributed legitimacy influences citizen cooperation separately from the instrumental influences of public evaluations of police performance, such as perceptions of the ability of the police to detect wrongdoing and effectively fight crime. ${ }^{22}$ Legitimacy is an important motivation for social control if it can contribute to our understanding of why people cooperate with the police beyond the influence of public assessments of police performance and the benefits that citizens enjoy from such performance. That is, we segregate the effects of police performance from the other components of police behavior and services. This hypothesis is tested separately for two aspects of cooperation: the willingness to help the police in their investigations of crime and the willingness of citizens to work with others in the community to collectively produce security.

Second, we examine whether the link between legitimacy and cooperation differs across ethnic groups. Researchers have identified racial differences in attitudes toward the police as a key characteristic of American communities, with minorities having lower levels of trust and confidence in the police. ${ }^{23}$ We assess whether these differences influence the degree to which police legitimacy shapes cooperation within the majority and minority communities. Indeed, residents in poor neighborhoods with high concentrations of racial and ethnic minorities experience different forms and strategies of policing, differences that may produce different views of the police independent of the outcomes of police-citizen interactions. ${ }^{24}$ We include these perceptions and experiences as explicit and separate components of a framework to explain differences by race in cooperation with the police and compliance with the law.

${ }^{22}$ Cf. Wesley G. Skogan, Asymmetry in the Impact of Encounters with Police, 16 PoLICING \& SoC'Y 99, 118-19 (2006) (finding that citizen evaluations of police services are asymmetrically influenced by perceptions of negative treatment ).

23 See BAYLEY \& MENDELSOHN, supra note 6, at 109-42 (1969) (finding ethnicity, but not sex or social class, correlated with negative perception of police); RONALD WEITZER \& STEVEN A. TUCH, RACE AND POLICING IN AMERICA 74-123 (2006) (examining views of racialized policing and perceptions of unequal justice); Steven A. Tuch \& Ronald Weitzer, The Polls-Trends: Racial Differences in Attitudes Toward the Police, 61 PUB. OPINION Q. 642, 647-48 (1997) (discussing Los Angeles-area and national studies on Blacks' versus Whites' perceptions and experiences of police brutality).

24 See WEITZER \& TUCH, supra note 23, at 119-23 (discussing roles of mass media and neighborhood crime concerns in shaping perceptions of racialized policing by Blacks and Hispanics); Faye Crosby, Stephanie Bromley \& Leonard Saxe, Recent Unobtrusive Studies of Black and White Discrimination and Prejudice: A Literature Review, 87 PSYCHOL. BULL. 546 (1980) (reviewing studies on anti-black prejudice); Jeffrey Fagan \& Garth Davies, Policing Guns: Order Maintenance and Crime Control in New York, in Guns, CRIME, AND Punishment IN AMERICA 21 (Bernard E. Harcourt ed., 2003); Jeffrey Fagan \& Garth Davies, Street Stops and Broken Windows: Terry, Race, and Disorder in New York City, 28 FordHAM URB. L.J. 457, 489-96 (2000) [hereinafter Fagan \& Davies, Street Stops] (analyzing New York City study showing "greater intensity of enforcement and over-enforcement against minority citizens" and suggesting "conflation of race, poverty, and disorder in policing policy"); Leonard Saxe et al., The Visibility of Illicit Drugs: Implications for CommunityBased Drug Control Strategies, 91 AM. J. PUB. HEALTH 1987, 1991-93 (2001) (discussing how differences in predictors for drug use versus visible drug sales affect policy). 
We argue, and show empirically in this article, that legitimacy develops from aspects of experience with policing that are distinct from instrumental judgments about police performance. We test the hypothesis that legitimacy is based upon public judgments about the policies and practices of the police. We test the notion that citizens' perceptions of the legitimacy of the police are, in reality, justicebased evaluations of the manner in which the police are thought to exercise their authority. A corollary question speaks to the policy implications of legitimacybased cooperation. To motivate such cooperation it is important to identify the antecedents of legitimacy, i.e., the degree to which legitimacy rests on a normative base and is a reflection of judgments about the appropriateness of police behavior.

\section{BACKGROUND}

\section{A. Why Are the Police Legitimate?}

Widespread suggestions that many among the American public lack high levels of "trust and confidence" in the legal system give special importance to legitimacy's role. ${ }^{25}$ This lack of trust and confidence is found to be especially high in the case of the courts and the criminal justice system and less striking with the police. ${ }^{26}$ However, all of these legal institutions show evidence of strong group differences-with minority group members expressing lower levels of trust and confidence. ${ }^{27}$ Professors Lawrence Bobo and Devon Johnson show evidence from general population surveys that African Americans show the lowest levels of trust, and Whites the highest. ${ }^{28}$ Hispanics occupy a middle range between these two groups. Discontent among minority populations is especially important since the

25 TYLER \& HUO, supra note 16 , at 5 ("In recent years the perception has grown that the relationship between the public and legal authorities is becoming more negative."); GARY LAFrEE, Losing Legitimacy: STREET CRIME AND tHe DECLINE of SOCIAL INSTITUTIONS IN AMERICA (1998) (discussing postwar crime trends and impact on social and political institutions); Tom R. Tyler, Public Mistrust of the Law: A Political Perspective, 66 U. CIN. L. Rev. 847, 848-53 (1998) [hereinafter Tyler, Public Mistrust] ("Recently, less than 10\% of the American public expressed 'a great deal' of confidence in the American legal system.").

26 See, e.g., Tyler, Public Mistrust, supra note 25, at 853 (discussing public opinion polls showing dissatisfaction with courts in general and local courts in particular).

27 James Garofalo, U.S. Dep't of Justice, Public Opinion ABout Crime: The Attitudes OF VICTIMS AND NONVICTIMS IN SELECTED CITIES 28 (1977) (reporting, from National Crime Survey results, a "very large" gap between white and black perceptions of police performance); HowARD SCHUMAN ET AL., RACIAL ATTITUDES IN AMERICA 139-62 (1985) (discussing survey results on civil rights issues); Lawrence D. Bobo \& Devon Johnson, A Taste for Punishment: Black and White Americans' Views on the Death Penalty and the War on Drugs, 1 Du BoIS REv. 151, 156-57 (2004) (discussing "substantial differences between Blacks and Whites" on views of police behavior and prosecutor and court treatment); Michael J. Hindelang, Public Opinion Regarding Crime, Criminal Justice, and Related Topics, 11 J. RES. CRIME \& DELINQ. 101 (1974); W.S. Wilson Huang \& Michael S. Vaughn, Support and Confidence: Public Attitudes Toward the Police, in AMERICANS VIEw CRIME AND JUSTICE (Timothy J. Flanagan \& Dennis R. Longmire eds., 1996).

28 See Bobo \& Johnson, supra note 27, at 168-72. 
need for both deference and cooperation is especially strong in these communities, where criminal activity is often found at its highest levels. ${ }^{29}$ While always a concern, in recent years the need to maintain legitimacy has been especially important to the police, the courts, and the legal system in seeking to leverage citizen trust and cooperation into the co-production of security.

The argument that legitimacy is a normative judgment flows from the classic work of Weber. ${ }^{30}$ He suggests that legitimacy develops from the manner in which authority is exercised. Weber argues that in modern society, authorities benefit when they are able to obtain cooperation from the people with whom they deal beyond the cooperation which they can obtain via their control of the power to shape behavior through the use of sanctions and incentives. It is desirable to also be able to secure cooperation through the manner in which they exercise their authority. In other words, they want to be able to call upon deference to authority that is "legitimized" in noninstrumental ways, such as via the procedures by which it is exercised. Similarly, Beetham regards legitimacy as the product of interactions between state and individual where both the subordinate and the empowered actor share social norms and the moral reasoning that informs them that the exercise of authority by the state is appropriate. ${ }^{31}$

These perspectives raise several challenges for empirical assessments of procedural justice by social scientists. Procedural justice reflects judgments about the manner in which authority is exercised. It includes judgments of the quality of decision-making, which includes neutrality: making decisions based upon facts and applying rules consistently. It also involves judgments about the quality of interpersonal treatment: respect, politeness, and consideration of one's views. Distributive justice also informs legitimacy; it involves the fairness and equity of the police delivery of services to persons across social and demographic groups. In this study, survey respondents were asked to indicate whether services were distributed fairly to people like the respondent. An unfair distribution could reflect either receiving too little or too much.

And, as with the general importance of legitimacy in shaping cooperation, it is again important to consider whether the role of procedural justice in shaping legitimacy differs between Whites and minorities. Based upon an analysis of people's personal experiences with the police, Tyler and Huo argue that both Whites and minorities evaluate their personal experiences similarly, by putting

29 Jeffrey Fagan, Crime and Neighborhood Change, in UNDERSTANDING CRIME TRENDS 81 (Arthur S. Goldberger \& Richard Rosenfeld eds., 2008); Kenneth C. Land, Patricia L. McCall \& Lawrence E. Cohen, Structural Covariates of Homicide Rates: Are There Any Invariances Across Time and Social Space?, 95 AM. J. of Soc. 922, 954 (1990); Robert J. Sampson \& Janet J. Lauritsen, Violent Victimization and Offending: Individual-, Situational-, and Community-Level Risk Factors, in 3 UNDERSTANDING AND PREVENTING VIOLENCE 1 (Albert J. Reiss, Jr. \& Jeffrey A. Roth eds., 1994).

30 See generally WEBER, supra note 14.

31 See BEETHAM, supra note 13, at 15-16 ("Power can be said to be legitimate to the extent that ... the rules can be justified by reference to beliefs shared by both dominant and subordinate ...."). 
weight on procedural justice and trust, ${ }^{32}$ while Sunshine and Tyler argue that Whites and minorities rely upon generally similar procedural justice evaluations when making overall evaluations of the police and the law. ${ }^{33}$ This study tests that argument using panel data from a general population.

\section{B. The Influence of Personal Experience with the Police}

Legitimate authority, when it exists, has a unique and important advantage when it motivates voluntary cooperation that is not dependent on instrumental criteria. $^{34}$ In other words it is not dependent upon people's judgments about the rewards or punishments that are likely to follow from engaging in cooperative behavior. To the degree that people are motivated by legitimacy, people cooperate because they feel it is the right thing to do, not because of material gains or loses. ${ }^{35}$ This perspective has been echoed by later social theorists, ${ }^{36}$ and is strongly supported by empirical evidence suggesting that legitimacy is based upon judgments about the procedural justice of the actions of authorities and institutions. $^{37}$

The suggestion that the legitimacy of authorities is linked to evaluations of the procedures that they use to make decisions and to how they deliver services receives widespread support in studies of the psychology of legitimacy. ${ }^{38}$ Those studies find that the key antecedents of assessments of the legitimacy of authorities are judgments about the fairness of the procedures those authorities use when making decisions. Studies further find that procedures are judged against ethical

32 TYLER \& HUO, supra note 16, at 175-76 (arguing that "feelings of procedural justice and motive-based trust" enhance voluntary deference to authorities).

${ }^{33}$ Sunshine \& Tyler, supra note 11, at 531-33 ("[W]hite and African American assessments of legitimacy were influenced by distributive justice. ...").

34 TOM R. TYLER, Psychology AND THE DEsign OF LEGAL INSTITUTIONS 9-20 (2008) (explaining the deterrence model and noting its problems).

35 Tyler \& Darley, supra note 19, at 708 (presenting "law-abiding society" as one in which people voluntarily defer to and cooperate with authority because of the belief that laws describe morally appropriate behavior).

36 See BEETHAM, supra note 13, at 26-29 (arguing that legitimate power provides moral and normative reasons for obedience, apart from incentives and sanctions); David Beetham \& Christopher Lord, Legitimacy and the European Union, in POLITICAL THEORY AND THE EUROPEAN UNION (Albert Weale \& Michael Nentwich eds., 1998).

37 Tyler, Why PeOPle OBEY, supra note 1, at 172 (concluding that "experiencing unfair procedures undermine[s] the role of legitimacy in maintaining compliance").

38 See generally E. ALLAN LIND \& TOM R. TYLER, THE SOCIAL Psychology OF PROCEdURAL JUSTICE (1988) (discussing studies demonstrating that individuals'. views of the system depend on justice of procedures as well as justice of outcome); TOM R. TYLER ET AL., SOCIAL JUSTICE IN A DIVERSE SOCIETY (1997) (discussing how fair procedures, and not just outcome faimess, is important to individual dignity and commitment to law); Tom R. Tyler \& Heather J. Smith, Social Justice and Social Movements, in 2 THE HANDBOOK OF SOCLAL PSYCHOLOGY 595 (Daniel T. Gilbert et al. eds., 4th ed. 1998). 
criterion of their appropriateness that are distinct from the favorability or fairness of the outcomes of such procedures. ${ }^{39}$

This literature suggests that evaluations of the procedural fairness and justice of the policies and practices of the police shape perceptions of their legitimacy. ${ }^{40}$ Further, the same studies suggest that it is such evaluations of procedural justice, rather than evaluations of the distributive justice of the allocation of police services, that is the key ethical judgment underlying legitimacy.

The procedural justice model of policing argues that the police can build general legitimacy among the public by treating people justly during personal encounters. This argument is based upon two empirical arguments. The first is that people evaluate personal experiences with the police by evaluating the fairness of police procedures. The second is that this means that by using fair procedures the police can increase their legitimacy, even if their policing activities involve restricting or sanctioning the people with whom they are dealing.

Others reject the notion that interaction, irrespective of its quality, affects the appraisal of police legitimacy or performance. Professor Wesley Skogan has recently claimed that positive experiences from personal encounters do not improve public evaluations of the police. ${ }^{41}$ Research in England by Professor Ben Bradford and colleagues tested Skogan's notion of asymmetry and produced the opposite result: the quality of interaction with police affects attributed legitimacy, and influences citizen engagement with police in the co-production of local security. ${ }^{42}$

39 TYLER \& HUO, supra note 16, at 57 (concluding from Chicago and California studies that "people are significantly more focused on the procedural justice of authorities' actions than [on] ... the favorability or fairness of their own outcomes" during encounters with police or the court); Tom R. Tyler, Procedural Justice, Legitimacy, and the Effective Rule of Law, 30 CRIME \& JUST. 283, 292 (2003) (observing that while faimess of outcome matters, procedural justice is "especially important in shaping people's willingness to defer to the decisions made by legal authorities"); Tom R. Tyler, Social Justice: Outcome and Procedure, 35 INT'L J. PSYCHOL. 117, 119-20 (2000) [hereinafter Tyler, Social Justice] (finding procedural justice factors more important than outcomes of police interaction, such as arrest, for assessment of legitimacy); Tom R. Tyler, What is Procedural Justice?: Criteria Used by Citizens to Assess the Fairness of Legal Procedures, 22 LAW \& SOC'Y REV. 103, 117 (1988) [hereinafter Tyler, What is Procedural Justice?] (finding that individuals distinguish perceptions of faimess from favorability of outcome).

40 See, e.g., TYLER \& HUO, supra note 16, at 204-08 (emphasizing importance of fair procedures in increasing public acceptance of police authority); $c f$. WEITZER \& TUCH, supra note 23, at 58-73 (discussing reasons behind perceptions of police misconduct).

41 Skogan, supra note 22, at 112 ("The impact of encounters is strongly asymmetrical. Having a positive experience helps little .... Having a bad experience hurts a great deal."). Skogan reaches these conclusions using cross-sectional survey data from a study of citizens in Chicago. Id. at 107-10. The absence of longitudinal or panel data suggests that citizen evaluations of policing could either precede or follow their encounter with police.

42 Ben Bradford, Jonathan Jackson \& Elizabeth A. Stanko, Contact and Confidence: Revisiting the Impact of Public Encounters with the Police, 18 POLICING \& SOC'Y (forthcoming 2008) (stating that "consistent with the procedural justice model[,] we also show that positively received contacts can improve perceptions of faimess and community engagement") (manuscript at 2 , 
The contrasting outcomes are a function of differences in their study designs and measurement strategies. Unlike most procedural justice research, Skogan does not distinguish between receiving a positive outcome and receiving positive treatment. Instead, Skogan conflates these factors, arguing that when people have a positive experience with the police, "including being treated fairly and politely, and receiving service that [is] prompt and helpful," there is no positive impact of that experience. ${ }^{43}$ In contrast, he suggests that negative experiences lower trust and confidence in the police, although it is not clear from his research whether such lower evaluations either promote compliance with legal rules or cooperation with legal actors. Instead, Skogan suggests that these findings have pessimistic implications for policing, since they suggest no easy route to building public trust and confidence. As he says, "this is bad news indeed for police administrators intent on solidifying their support among, voters, taxpayers and the consumers of police services." 44

Skogan's claim that positive experiences do not influence evaluations of the police contradicts the arguments of a recent National Research Council review of a rich body of empirical evidence on the determinants of effective policing. ${ }^{45}$ This review went beyond the normative basis for valuing procedurally "fair policing" to cite evidence that policing that increased police legitimacy through procedural justice was both necessary and possible. ${ }^{46}$

Certainly, the implications of Skogan's argument are contrary to the argument based upon procedural justice research that the police ought to be trained to act in ways the public experiences as being just and encouraged to do so during personal encounters with members of the public. While much procedural justice research has not been longitudinal in nature, cross-cultural findings have been used to argue that treating people fairly builds their trust and confidence in the police. ${ }^{47}$ And, some studies have been longitudinal in nature. ${ }^{48}$

In this study, we use panel data from interviews one year apart to test the two key empirical assumptions underlying procedural justice research. The first is that procedural justice is the central factor that shapes people's reactions to their experiences with the police. The second is that, if people experience positive procedural justice during a personal experience with the police, their trust and confidence in the police increases, independent of the valence of their personal outcomes.

available

http://www.lse.ac.uk/collections/methodologyInstitute/pdf/JonJackson/policing_and_society_08.pdf).

43 Skogan, supra note 22 , at 99.

44 Id.

45 FAIRNESS AND EFFECTIVENESS IN POLICING, supra note 8.

46 Id. at 109-54.

47 TYLER \& HUO, supra note 16, at 198-208.

48 TYLER, WHY PEOPLE OBEY, supra note 1. 
While the Skogan study is based on a number of large datasets, all the studies he considers are cross-sectional. In other words all the judgments are measured at one point in time, after the experience. Skogan infers the impact of experience by comparing the mean trust and confidence of people varying in the nature of their recent personal experience with the police. Cross-sectional research frustrates statistical identification of the effects of procedural justice and outcomes on evaluations of police legitimacy by overlooking causal order. ${ }^{49}$ Imagine, for example, that people's views about the legitimacy of the police shape their judgments about their experience, rather than that legitimacy judgments result from judgments about experience. Cross-sectional data cannot distinguish among these two arguments.

\section{This Study}

We test the impact of personal experience on evaluations of legitimacy and cooperation with the police using a longitudinal design in which people are interviewed both prior to and following their personal experiences with the police. Our hypothesis is that experiencing procedural justice will have positive consequences upon people's views about the police, irrespective of whether people received favorable or unfavorable outcomes.

The study has three goals. First, we extend prior arguments concerning the value of legitimacy in shaping compliance to include an examination of the influence of legitimacy on cooperative behavior. Tyler uses panel data and argues that legitimacy shapes general compliance. ${ }^{50}$ Sunshine and Tyler use crosssectional data to extend this argument to cooperation, but do not distinguish cooperation with the police from cooperation with the community. ${ }^{51}$ This study distinguishes among forms of cooperation and uses a panel design to test the influence of legitimacy on these different types of cooperation. That influence is compared to the influence of instrumental judgments about the police and identification with one's neighborhood.

Second, we explore the psychology of cooperation with the police. Several studies claim that ratings of procedural justice following experiences with police shape legitimacy; here, we test the extent to which this argument is true using panel data. ${ }^{52}$ And while other studies use narrow or single indicia of procedural

49 Charles F. Manski, Identification Problems in the Social Sciences (1995) (showing the importance of specification of causal order and the elimination of endogenous and simultaneous influences to establish causal ordering between behavioral factors); see also WLLIAM R. SHADISH, Thomas D. CoOK \& Donald T. CAMPBEll, EXPERIMENTAL AND QUASI-EXPERIMENTAL DESIGNS FOR GENERALIZED CAUSAL INFERENCE (2d ed. 2002).

50 TYLER, WHY PEOPLE OBEY, supra note 1, at 57-68.

51 Sunshine \& Tyler, supra note 11, at 525-34.

52 Id. See also TYLER, WHY PEOPLE OBEY, supra note 1, at 94-112 (finding that personal experiences with police or court officials influences views about their legitimacy); TYLER \& HUO, supra note 16, at 123-38 (suggesting that generalized legitimacy develops from experiences of fair 
justice, we examine the role of two aspects of procedures that have received less empirical attention: the quality of police decision making and the quality of interpersonal treatment of citizens by police. ${ }^{53}$

Finally, we examine whether and how ratings of the fairness of procedures during personal experiences with the police enhance or attenuate perceived legitimacy. We consider the effects of police procedure on perceived legitimacy when either positive or negative outcomes are being delivered. Tyler and Huo argue, based upon cross-sectional surveys, that both prior legitimacy and procedural justice during personal experiences with the police impact subsequent legitimacy, a conclusion rejected by Skogan. ${ }^{54}$ Here, we use longitudinal data to conduct a more efficient estimation and identification of these effects, and accordingly offer a more rigorous test of this argument that considers both direct and indirect influences of legitimacy.

Looking ahead, we show that the procedural justice-legitimacy connection provides a robust framework for understanding the basis of public cooperation with the police similar to the basis of compliance that has already been established. If so, then a general model of police behavior can be identified, a model which indicates how the police can conduct themselves so as to encourage public cooperation both via compliance with the law, and through active cooperation with the police. We assume this link is normative and widely shared, and accordingly will be evident among both white and minority respondents.

\section{RESEARCH DESIGN}

A random sample of New York City residents were interviewed by telephone at two points in time. ${ }^{55}$ The first wave of interviews occurred in 2002, the second in 2004. The Wave 1 sample of 1,653 respondents was drawn from a stratified random sample of residential telephone numbers in the City. Non-white residents were oversampled to produce a high proportion of Hispanic, and African-

and trustworthy conduct on the part of legal authorities); Sunshine \& Tyler, supra note 11, at 534-36 (same).

53 In this study, we do not view these interactions as dynamic exchanges where both police and citizens respond to each others' behaviors. Such dyadic interactions are important and will bear on both how the police officer and the citizen react to each other, and also how each rates his or her behavior. However, the complications and challenges of a research protocol that would integrate such interactions in a study of citizens' reactions to police are daunting and should be obvious. Rather, we rely here on citizens' reports and evaluations of the quality of treatment they received from the police and set aside any effects of the citizens' behavior on the responses and reactions of the police officer in the situation or encounter.

54 TYLER \& HUO, supra note 16, at 123-29 (reporting survey results suggesting that general favorable attitudes feed back into specific situations of interactions with legal authorities); Skogan, supra note 22 , at 106.

55 The Random Digit Dialing method sampled only from eligible telephone numbers, and did not include cell phones. If an answering machine was reached, respondents were recalled up to 20 times. 
American respondents. Interviews were conducted in English or Spanish, based on the language preference of the respondent. The ethnicity of the respondent and the interviewer were not matched. When a home was reached, the adult in the household with the most recent birthday was interviewed. The response rate for the wave one survey was $64 \%$ of eligible respondents.

Approximately one year following the first interview, attempts were made to recontact and reinterview all of the respondents interviewed. Among those identified and recontacted, the response rate for the Wave 2 sample was $53 \%(\mathrm{n}=$ 879). Although efforts were made to trace and re-interview those respondents who had moved, only those respondents still living within the same neighborhood were included in this analysis $(n=830)$. A comparison of the 830 re-interviewed to the original Wave 1 sample indicates no statistically significant differences in ethnicity, gender, age, income, or education. ${ }^{56}$ Methodological details about the survey are provided in the Appendix.

\section{A. Measures}

Respondents at each wave answered a series of questions presented over the telephone with fixed response alternatives. Questions examined a variety of issues, including police legitimacy; indices of police performance; the quality of the respondent's connection with their neighborhood; the distributive and procedural justice of the police; and cooperation with the police and with others in the neighborhood. The variables were assessed using identical questions at both waves.

In addition, respondents in Wave 2 were asked if they had had any personal contact with the police during the one-year period between interviews. Of the 830 Wave 2 respondents, $255(30.7 \%)$ had had at least one personal experience. Those with personal experience were asked about the procedural justice of that experience, as well as the fairness of its outcome. The questions are presented in the appendix. Those respondents without experience were excluded from this analysis. As we discuss below, we estimate propensity scores to address nonrandomness in the population of persons who did and did not have contact with the police at Wave 2. We developed separate propensity scores for police-initiated and citizen-initiated contacts. Citizen-initiated contacts included requests for information and attempts to file complaints with the police.

Dependent variables were a series of items asking about four types of cooperative behavior: willingness to help the police by reporting crime and criminals; willingness to help the police by working in community groups to fight crime; compliance with regulations (e.g., speeding); and compliance with laws (e.g., drug use).

The independent variables were organized in two domains: legal orientation and attitudes toward the police, and neighborhood crime problems and condition. 
The first domain included measures of judgments about the legitimacy of the police; judgments about police performance; and background information. The legitimacy of the police was assessed through scales indexing three dimensions: obligation to defer to police directives and to the law, trust and confidence in the police, and identification with the police.

Three aspects of police performance were measured: beliefs about the frequency with which the police caught those who broke rules/laws, judgments about how effective the police were in combating crime, and evaluations of neighborhood conditions. The second domain included questions about crime problems in the neighborhood, neighborhood ties, and the physical condition of the neighborhood. Respondents were also asked to indicate their age, education, income, and ethnicity. Gender was determined by the interviewer during the telephone interview.

The three indices of legitimacy-obligation, trust and confidence, and identification with the police-were found to be highly correlated (average $\mathrm{r}=0.50, \mathrm{p}<.000$ ). Accordingly, a single overall indicator of legitimacy was formed. We also estimated three dimensions of crime and criminal justice conditions: fear of crime, neighborhood social and physical conditions, and sanction risk. Two dimensions-fear of crime and physical conditions-were correlated $(r=0.44, p<.000)$ and were collapsed into a single measure. These indicators were distinct from sanction risk $(\mathrm{r}=.000, \mathrm{p}=\mathrm{n}$.s.). As a result, we treated sanction risk as a distinct indictor.

\section{B. Data Analysis}

Data were analyzed using Ordinary Least Squares [OLS] to assess relationships across the two waves. In the first wave analysis, we estimated OLS regressions cross-sectionally to identify factors that shaped baseline measures of legitimacy, compliance and cooperation.

We next estimated OLS regressions to identify the effects of procedural justice and outcomes on Wave 2 legitimacy, cooperation and compliance. Only 255 of the 830 respondents had police contact at Wave 2. Accordingly, we constructed propensity scores to account for the non-randomness of exposure to the police. ${ }^{57}$ We estimated the probability of police contact using logistic regression with predictors including Wave 1 cooperation, legitimacy, the neighborhood crime and social conditions measures, and demographics. ${ }^{58}$ We

57 See Richard Berk, Azusa Li \& Laura J. Hickman, Statistical Difficulties in Determining the Role of Race in Capital Cases: A Re-analysis of Data from the State of Maryland, $21 \mathrm{~J}$. Quantitative Criminology 365 (2005); Paul R. Rosenbaum \& Donald B. Rubin, The Central Role of the Propensity Score in Observational Studies for Causal Effects, 70 BIOMETRIKA 41 (1983); see also Richard A. BERK, REgRession ANAl ysis: A CONSTRUCTIVE CRITIQUE (2004).

58 We used dummy variables for African-American and Hispanic ethnicity to account for the disproportionate contact of non-white New Yorkers with the police during this period. See Fagan \& Davies, Street Stops, supra note 24. 
estimated separate propensity scores for police-initiated and citizen-initiated contacts, given obvious differences in the voluntariness of each type of contact. In estimating the effects of police contact on legitimacy and cooperation, we follow Bang and Robins ${ }^{59}$ and Indurkhya et al..$^{60}$ we use the inverse probability of treatment as the propensity score for the group with police contact, and the inverse of one minus the probability for the group without contact. This procedure allows us to adjust for collinearity between police contact and the factors that might predict each type of police contact.

\section{RESULTS}

\section{A. Is Cooperation Distinct from Compliance?}

Two types of cooperation were examined: compliance with the law and cooperation with the police. Conceptually, there is some overlap in these constructs and items are likely to be internally correlated. Accordingly, we used principle components factor analyses with varimax rotation and maximumlikelihood estimation to identify a parsimonious set of non-redundant variables to better represent the underlying dimensions of the various items. This procedure yielded four non-overlapping dimensions. These analyses were done initially on the Wave 1 measures. Because we were interested in stability and change over time, the factor analyses included only the 830 respondents who completed both waves. However, an analysis of the larger group of Wave 1 only respondents produced a similar factor structure. The panel respondents are shown in Table 1 $(\mathrm{N}=830)$.

59 Heejung Bang \& James M. Robins, Doubly Robust Estimation in Missing Data and Causal Inference Models, 61 BIOMETRICS 962, 965 (2005).

00 Alka Indurkhya, Nandita Mitra \& Deborah Schrag, Using Propensity Scores to Estimate the Cost-Effectiveness of Medical Therapies, 25 STAT. MED. 1561 (2006). 
Table 1. Principle Components Factor Analysis on Cooperation and Compliance Behaviors (Rotated Factor Scores) ${ }^{\mathrm{a}}$

\begin{tabular}{|c|c|c|c|c|}
\hline Factor & 1 & 2 & 3 & 4 \\
\hline \multicolumn{5}{|l|}{ If the situation arose, how likely would you be } \\
\hline & & & .82 & \\
\hline \multicolumn{5}{|l|}{$\begin{array}{l}\text { Call the police to report a crime that was } \\
\text { occurring. }\end{array}$} \\
\hline Help the police to find a criminal. & & & .72 & \\
\hline Report suspicious activity to the police. & & & .77 & \\
\hline Volunteer time to help the police. & & .85 & & \\
\hline Patrol the streets with others. & & .83 & & \\
\hline $\begin{array}{l}\text { Attend community police meetings about } \\
\text { crime. }\end{array}$ & & .68 & & \\
\hline \multicolumn{5}{|l|}{ How often do you follow rules concerning... } \\
\hline Where you park your car. & & & & .75 \\
\hline How you dispose of trash. & & & & .74 \\
\hline Speeding or breaking traffic laws. & & & & .61 \\
\hline Making too much noise at night. & .60 & & & \\
\hline Not buying stolen items on the street. & .81 & & & \\
\hline Not stealing from stores or restaurants. & .86 & & & \\
\hline Not using illegal drugs. & .85 & & & \\
\hline Explained variance & 25.08 & 18.28 & 9.94 & 9.88 \\
\hline Eigenvalue & 3.26 & 2.38 & 1.29 & 1.28 \\
\hline
\end{tabular}

a. Wave 1 items only, $\mathrm{N}=830$. Pairwise deletion. Varimax rotation. 
Four factors underlie the cooperation questions: helping to identify criminals; helping the community combat crime; complying with non-criminal regulations (parking laws, trash removal); and complying with more serious criminal laws (stealing; drug use). Compliance and cooperation appear to be largely distinct from one another, suggesting that the reasons why people obey the law may differ from why they may actively engage with police in the social regulation of crime. In fact, two factors within each of these domains were identified, suggesting further complexity and dimensionality in law-related behaviors. Accordingly, we extend prior analyses of law-related compliance to examine the social psychology of two dimensions of cooperation: helping the police and helping others in the neighborhood.

Based on the configuration of items in the factor analysis, we next constructed scales for each of the four factors. First, two helping subscales were created: helping to locate criminals and report crimes (three items, alpha $=0.69$ ); and working with others in the community to fight crime (three items, alpha $=0.75$ ). Two scales of compliance were created: following non-criminal regulations (three items; alpha = 0.55); and following criminal laws (four items-making excessive noise; buying stolen goods; taking items from stores; using drugs-alpha $=0.81$ ). Table 2 shows that the four scales were generally moderately correlated at Wave 1 : the average correlation was $r=0.09$.

Table 2. Correlation Matrices for Cooperation and Compliance Scale (Mean, Standard Deviation, R, two-tailed) ${ }^{\mathrm{a}}$

\begin{tabular}{|c|c|c|c|c|c|}
\hline & & \multicolumn{4}{|c|}{ Correlations } \\
\hline & Mean (SD) & 1 & 2 & 3 & 4 \\
\hline 1. Comply with minor laws & $4.37(0.78)$ & -- & & & \\
\hline 2. Comply with major laws & $4.59(0.82)$ & $0.39 * * *$ & --- & & \\
\hline 3. Help the police fight crime & $3.57(0.60)$ & $0.12 * * *$ & $0.16 * * *$ & $=$ & \\
\hline 4. Help neighbors & $2.79(0.85)$ & 0.06 & 0.02 & $0.33 * * *$ & $\ldots$ \\
\hline
\end{tabular}

Significance: ${ }^{*} \mathrm{p}<.05 ;{ }^{* *} \mathrm{p}<.01 ;{ }^{* * *} \mathrm{p}<.001$

a. Analysis only for Wave 1 data, $\mathrm{N}=830$ 
Since the intensity and tactics of policing in New York City tended to vary by neighborhood social and demographic factors, ${ }^{61}$ we also examined the properties of and correlations among these scales separately for minority and white samples. Results indicate that the scale properties and correlations are similar for white and non-white respondents.

\section{B. Why Do People Cooperate with the Police and with Others in Their Communities?}

Given the distinction between cooperation and compliance, we turn next to examining the social psychology of cooperation. Regression analysis was used to explore the psychological antecedents of cooperation. The analysis took advantage of the panel aspects of the study by examining the influence of time two measures of legitimacy, crime conditions, risk, and identification with neighborhood upon measures of cooperation controlling upon time one measures of the same judgments. In addition, time one measures of the appropriate form of cooperation were included. Finally, an interaction term was included to examine ethnicity effects (i.e., whether legitimacy had a different influence within the different ethnic groups).

The results are shown in Table 3. They indicate that legitimacy shaped willingness to help the police $(\mathrm{p}<.001)$ and willingness to work with the community $(\mathrm{p}<.001)$. In neither case was there a significant legitimacy-byethnicity interaction, suggesting that the influence of legitimacy was similar among both majority and minority respondents. 
Table 3. OLS Regression on the Antecedents of Helping the Police and Helping the Community (b, SE)

\begin{tabular}{|c|c|c|c|c|c|c|}
\hline & \multicolumn{3}{|c|}{ Help the Police } & \multicolumn{3}{|c|}{ Help the Community } \\
\hline & $b$ & $S E$ & $p$ & $b$ & $S E$ & $p$ \\
\hline \multicolumn{7}{|l|}{ Wave 2} \\
\hline Legitimacy & .236 & .058 & $* * *$ & .263 & .088 & $* *$ \\
\hline Legitimacy * Ethnicity $^{\mathrm{b}}$ & .050 & .069 & & .121 & .105 & \\
\hline Crime conditions & .024 & .042 & & .230 & .063 & $* * *$ \\
\hline Risk & .016 & .024 & & .136 & .036 & $* * *$ \\
\hline Identification-neighborhood & -.001 & .035 & & .182 & .053 & $* * *$ \\
\hline \multicolumn{7}{|l|}{ Wave 1} \\
\hline Cooperation & .390 & .031 & $* * *$ & .537 & .030 & $* * *$ \\
\hline Legitimacy & .027 & .047 & & -.226 & .072 & $* *$ \\
\hline Crime conditions & .004 & .041 & & -.184 & .063 & $* *$ \\
\hline Risk & .001 & .018 & & .010 & .028 & \\
\hline Identification-neighborhood & .078 & .029 & $* *$ & -.060 & .051 & \\
\hline \multicolumn{7}{|l|}{ Demographics } \\
\hline Gender & -.010 & .032 & & -.024 & .048 & \\
\hline Age & .004 & .015 & & .055 & .022 & $*$ \\
\hline Education & -.008 & .012 & & .034 & .018 & \\
\hline Income & -.010 & .009 & & -.002 & .014 & \\
\hline Ethnicity & .123 & .205 & & .290 & .310 & \\
\hline Adjusted R-squared & & $34 \%$ & & & $43 \%$ & \\
\hline
\end{tabular}

a. $\mathrm{p}<.05 ;{ }^{* *} \mathrm{p}<.01 ;{ }^{* * *} \mathrm{p}<.001$. All respondents $(\mathrm{n}=830)$

b. Ethnicity is a binary variable for non-white versus white (white $=0$ ). 
These findings supported the hypothesis that those members of the public who evaluated the police as being more legitimate were more cooperative with the police. They were cooperative first because they helped the police by reporting crime and criminals and second because they worked with others in their community to fight crime. The panel nature of the design allows us to demonstrate that legitimacy at time one shapes behavior at time two. Hence, attitudes are influencing later actions.

\section{Antecedents of Legitimacy}

The findings outlined above suggest the importance of understanding the factors that shape public judgments about the legitimacy of the police and the law, since whether or not people viewed the police as legitimate shaped whether or not they cooperated with police in their neighborhood. As before the panel nature of the design allows us to show that time one identification shapes later actions (measured at time two). In this study two models of the antecedents of legitimacy were contrasted: an instrumental performance model and a non-instrumental procedural justice model.

One model was a performance model of legitimacy. This model hypothesized that legitimacy itself was linked to the quality of police performance. If so, then the findings would not point to new approaches to motivating cooperation, since instrumental issues would define legitimacy. A performance model of policing would link public views about cooperation to their judgments of the effectiveness of police performance in fighting crime and urban disorder. It would suggest that to be viewed as legitimate the police need to communicate to those in the community that they can credibly punish wrongdoers, as well as that they are effectively fighting crime. The broken windows model of policing, for example, would link public evaluations of the police to public judgments about whether crime and disorder was being effectively dealt with by the police. ${ }^{62}$

This analysis compared such a performance based model to a model of legitimacy suggesting that legitimacy was linked to evaluations of the normative quality of police policies and practices-to the justice of police actions. Drawing upon the psychological literature, the normative approach linked legitimacy to assessments of the manner in which the police exercised their authority-to judgments about procedural justice. While both distributive and procedural justice were potential normative bases for evaluating legal authorities, prior research suggests that the public evaluates legal authorities primarily against criteria of procedural justice. $^{63}$

62 Kelling \& COLES, supra note 5.

63 Sunshine \& Tyler, supra note 11; TYLER, WhY PEOPLE OBEY, supra note 1; Tom R. Tyler, Public Trust and Confidence in Legal Authorities: What Do Majority and Minority Group Members Want from the Law and Legal Institutions?, 19 BEHAV. SCl. \& L. 215 (2001) [hereinafter Tyler, Public Trust]. 
Because they have been important in past discussions of policing ${ }^{64}$ judgments of the distributive faimess of police actions, i.e., the degree to which the police were viewed as allocating their services fairly, were also included to test for a possible role of the alternative normative model-that the public reacts to the distributive fairness of the allocation of police services. Within the social psychological literature distributive and procedural justice are viewed as the two types of justice that are potential antecedents of cooperation. ${ }^{65}$

Drawing on psychological models of procedural justice, two dimensions were distinguished: judgments about the justice of the decision making aspects of procedures and judgments about the justice of the interpersonal treatment that people receive from authorities. ${ }^{66}$ Justice involving the decision-making element in procedures links procedural justice to issues such as the degree of neutrality, even-handedness, consistency in the application of rules, and the absence of personal bias or prejudice. Justice in interpersonal treatment links procedural justice to respect for people's rights and dignity and consideration of their needs and concerns. Distributive justice refers to the fairness of the distribution of services. In this case, respondents were asked whether they received a fair level of services, or whether they received too little or too much.

The relationship between the procedural justice of police policies and practices and public evaluations of the legitimacy of the police was tested using regression analysis. The focus of this analysis is on time two evaluations of legitimacy. This analysis again takes advantage of the panel aspects of the study by examining the influence of time two evaluations of quality of decision making; quality of interpersonal treatment; crime concerns; sanctioning risk; and distributive justice to the respondent upon time two legitimacy, controlling on time one evaluations of these same qualities. And, also controlling upon time one measures of legitimacy. Demographic variables were also included in the analysis as controls. Finally, the analysis included interaction terms to test whether the influence of the indices of procedural justice had a differential influence among white and minority respondents.

The results of the analyses indicated that public evaluations of the justice of police decision making and the justice of the manner that the police treat members of the public both shaped police legitimacy (see Table 4). Respondents viewed the police as more legitimate if they made decisions fairly $(p<.001)$ and if they treated people justly $(\mathrm{p}<.001)$. 
Table 4. OLS Regression on the Antecedents of Legitimacy (b, SE)

\begin{tabular}{|c|c|c|c|}
\hline & $b$ & $S E$ & $p$ \\
\hline \multicolumn{4}{|l|}{$T 2$} \\
\hline Quality of decision making & .141 & .033 & $* * *$ \\
\hline Quality of interpersonal treatment & .158 & .030 & $* * *$ \\
\hline QDM * ethnicity & .078 & .056 & \\
\hline QIT * ethnicity & -.024 & .054 & \\
\hline Police performance & .034 & .026 & \\
\hline Sanctioning risk & .033 & .015 & * \\
\hline Distributive justice to groups & .056 & .019 & $* *$ \\
\hline \multicolumn{4}{|l|}{$T I$} \\
\hline Legitimacy & .475 & .029 & $* * *$ \\
\hline Quality of decision making & -.038 & .016 & * \\
\hline Quality of interpersonal treatment & -.015 & .017 & \\
\hline Police performance & -.025 & .025 & \\
\hline Sanctioning risk & -.005 & .012 & \\
\hline Distributive justice to groups & -.019 & .018 & \\
\hline \multicolumn{4}{|l|}{ Demographics } \\
\hline Gender & .003 & .020 & \\
\hline Age & .030 & .009 & $* * *$ \\
\hline Education & -.007 & .008 & \\
\hline Income & .009 & .006 & \\
\hline Ethnicity & .087 & .066 & \\
\hline Adjusted R-squared & \multicolumn{2}{|c|}{$71 \%$} & \\
\hline
\end{tabular}

a. $\mathrm{p}<.05 ;{ }^{* *} \mathrm{p}<.01 ;{ }^{* * *} \mathrm{p}<.001$. All respondents $(\mathrm{n}=830)$ 


\section{Personal Experience with the Police}

During the year between the two interviews, 255 of the 830 respondents $(31 \%)$ had at least one personal experience with the police. When asked to discuss their most recent experience, $45 \%$ talked about a situation in which they contacted the police for help; $21 \%$ talked about a situation in which they were stopped by the police; and $35 \%$ talked about a situation in which they contacted the police to make a complaint about some problem or situation.

It was possible to further test the role of procedural justice in shaping legitimacy and cooperation using this subgroup of respondents. In this analysis those respondents who had no personal experience were excluded. Respondents were asked to make four judgments about their personal experience: whether decisions were made via just decision making procedures; whether they received just interpersonal treatment; whether the outcome of their experience was fair; and whether the outcome of their experience was favorable.

While the prior analysis in this paper focused upon general judgments about the outcomes produced by the police (i.e., lowering crime), this examination of personal experiences uses a more direct focus upon the favorability of police decisions when dealing personally with the respondent. The two indicesoutcome fairness and outcome favorability-were assessed. They were found to be highly correlated $(\mathrm{r}=0.83)$, so the analysis focused upon a single indicator that combined outcome favorability and outcome fairness.

Using a variable reflecting the two aspects of procedural justice-quality of decision making and quality of interpersonal treatment-the analysis first examined the influence of procedural justice on decision acceptance. The goal of this analysis is to replicate the widely found linkage between procedural justice and decision acceptance.

This analysis considered only judgments made during the second, post experience, interview. This parallels most research on the influence of procedural justice, which only considers post-experience judgments. ${ }^{67}$ Respondents were asked about: overall procedural justice (a combined index of quality of decision making and quality of treatment), outcome favorability, decision acceptance, and the intention to complain.

Using that data it was found that those who received favorable/fair outcomes were more likely to accept them $(p<.001)$, as were those who experienced procedural justice $(\mathrm{p}<.001)$. Further, those who received favorable/fair outcomes were less likely to want to complain $(p<.001)$, as were those who experienced fair procedures $(\mathrm{p}<.001)$. Overall, $82 \%$ of the variance in decision acceptance and $37 \%$ of the variance in complaining behavior was explained.

So, as in prior studies, procedural justice encouraged decision acceptance and led people to feel less motivated to complain. ${ }^{68}$ And, it had an influence that was

67 TYLER \& HUO, supra note 16; Skogan, supra note 22.

68 TYLER \& HuO, supra note 16. 
distinct from the favorability/fairness of the outcome. In addition, people were more willing to accept favorable outcomes.

Does prior legitimacy shape decision acceptance? A regression analysis including outcomes, procedural justice and prior legitimacy indicates that prior legitimacy plays no direct role in shaping decision acceptance or the likelihood of complaining. However, prior legitimacy is directly related to later judgments that the outcome was more favorable $(r=.37, p<.001)$ and that the procedures were fairer $(r=.50, p<.001)$. In a causal analysis prior legitimacy shapes both of these experience based evaluations and, through that indirect influence, has an impact upon decision acceptance and interest in complaining. Of course, if experience based judgments were not included in the model, prior legitimacy was linked to decision acceptance $(r=.40, p<.001)$ and interest in complaining $(r=-.23, p<$ $.001)$.

Because the encounters were not observed, it is not possible to distinguish between two reasons for the connection between prior legitimacy and evaluations of personal experience. One reason is that the encounters may have been different. Those who view the police as legitimate, for example, may approach them more positively, and create better interactions. Or, they may have the same type of interactions, but perceive them more favorably. Without direct evidence it is not possible to distinguish between these two possibilities.

\section{Must Regulation Undermine Legitimacy?}

One of the most promising arguments developing from the models outlined is that the police can deliver negative outcomes to the public in ways that will enhance legitimacy, if they exercise their authority via fair procedures. This argument, advanced by Huo and Tyler and others, ${ }^{69}$ has not been disputed by Skogan to the extent that he agrees that negative experiences influence people. ${ }^{70}$ Interestingly, Skogan is concerned not so much with negative outcomes, the traditional focus of concern, but with the limitations of favorable outcomes. In the case of positive outcomes, he argues that positive experiences have little influence upon views about the police, while negative experiences have a large influence. Based upon an analysis of cross-section data comparing people with no experience to those with positive experience Skogan argues that favorable experiences do not enhance trust and confidence in the police. However, as noted, Skogan does not distinguish within experiences, separating the effects of just procedures from that of favorable or unfavorable outcomes. ${ }^{71}$

To address this issue we need to examine whether the procedural justice of experience matters among those receiving positive and negative outcomes. The panel design further allows the relationship between procedural justice and

\footnotetext{
69 See, e.g., TYLER \& HUO, supra note 16.

70 Skogan, supra note 22, at $115,119$.

71 Id.
} 
decision acceptance to be examined taking account of prior legitimacy. A regression analysis was used to explore the influence of time one legitimacy and the procedural justice of the experience (a summary of the two experience based indices-decision making and treatment) upon time two legitimacy. And, as noted, the analysis distinguished between those respondents who received either favorable or unfavorable outcomes. First we need to examine whether procedural justice influences legitimacy. The results are shown in Table 5. They indicate that both procedural justice and prior legitimacy shape post experience legitimacy. As we might expect, outcome favorability has no influence.

Table 5 presents a combined analysis for overall procedural justice and separate analyses for quality of decision making and quality of interpersonal treatment. Irrespective of which analysis is considered, no effects for outcome valence/fairness are found. However, the analysis that includes decision making and interpersonal treatment as two factors suggests that it is interpersonal treatment that is the most important factor shaping reactions to experiences.

Table 5. OLS Regression of Personal Experience and T1 Legitimacy on T2 Legitimacy for Persons with Police Contact $(b, \mathrm{SE})^{\mathrm{a}}$

\begin{tabular}{|c|c|c|c|c|c|c|}
\hline & \multicolumn{6}{|c|}{ T2 Legitimacy } \\
\hline & $b$ & $S E$ & $p$ & $b$ & $S E$ & $p$ \\
\hline Procedural justice ${ }^{b}$ & .17 & .05 & $* * *$ & --- & - & \\
\hline Quality of decision making & -.. & --- & & .00 & .05 & \\
\hline Quality of interpersonal treatment & --- & --. & & .16 & .05 & $* * *$ \\
\hline Outcome valence/ outcome fairness & .03 & .04 & & .02 & .04 & \\
\hline Gender & -.02 & .04 & & -.02 & .04 & \\
\hline Age & -.06 & .02 & $* * *$ & -.06 & .02 & \\
\hline Education & .02 & .02 & & .02 & .02 & \\
\hline Income & .00 & .01 & & .00 & .01 & \\
\hline Ethnicity & .01 & .05 & & .00 & .05 & . \\
\hline T1 Legitimacy & .47 & .05 & $* * *$ & .46 & .05 & $* * *$ \\
\hline Adjusted R.-sq. & & $58 \%$ & & & $58 \%$ & \\
\hline
\end{tabular}

a. ${ }^{*} \mathrm{p}<.05 ; * * \mathrm{p}<.01 ; * * * \mathrm{p}<.001$.

b. The Procedural Justice scale is a combination of the Quality of Decision Making and Quality of Interpersonal Treatment.

The best way to address the question whether experience changed views about the legitimacy of the police was to look at change in legitimacy among those whose experience has a favorable or an unfavorable outcome (see Table 6). This analysis directly tests the suggestion that favorable experiences do not increase trust and confidence in the police. In addition, we can also examine the influence of experience among those who initiated their contact with the police, in comparison to those for whom the contact was initiated by the police.

There are two approaches that we might potentially use in the analysis. First, we can ignore those without personal experience. Second, we can assume that 
those people would, if they had had a personal experience, have had an average experience. $^{72}$ Those two approaches are shown in Table 6 , with all respondents shown in column one, and only those with experience in column two. Both analyses reinforce our prior finding-procedural justice shapes post-experience legitimacy, controlling upon pre-experience legitimacy. One way to understand the Skogan argument is that it predicts an interaction in which procedural justice has a lower impact at high levels of outcome favorability. ${ }^{73}$ None of the regression equations find a significant interaction. This suggests that the influence of procedural justice is constant across outcome favorability. ${ }^{74}$

72 Using the time one measures we can predict $2 \%$ of the variance in the likelihood that a respondent will later have a police-initiated contact. Thus, contacts with the police at time two appear to be random. Time one values and cooperation have no influence upon the likelihood of later policeinitiated contact, and the only significant demographic is gender, with men more likely to have police-initiated contact. With respondent-initiated contact we can also explain $2 \%$ of the variance. Again, time one values and cooperation have no influence upon the likelihood of a respondent later contacting the police. However, women, older respondents, and better-educated respondents are significantly more likely to initiate contact with the police.

73 See Skogan, supra note 22.

74 The analysis shown in Table 6 also distinguishes between those who initiate contact and those who do not. The results are the same among both groups. Because the sample of policeinitiated contacts was small ( 46 people) the equation testing that effect did not include background factors. 


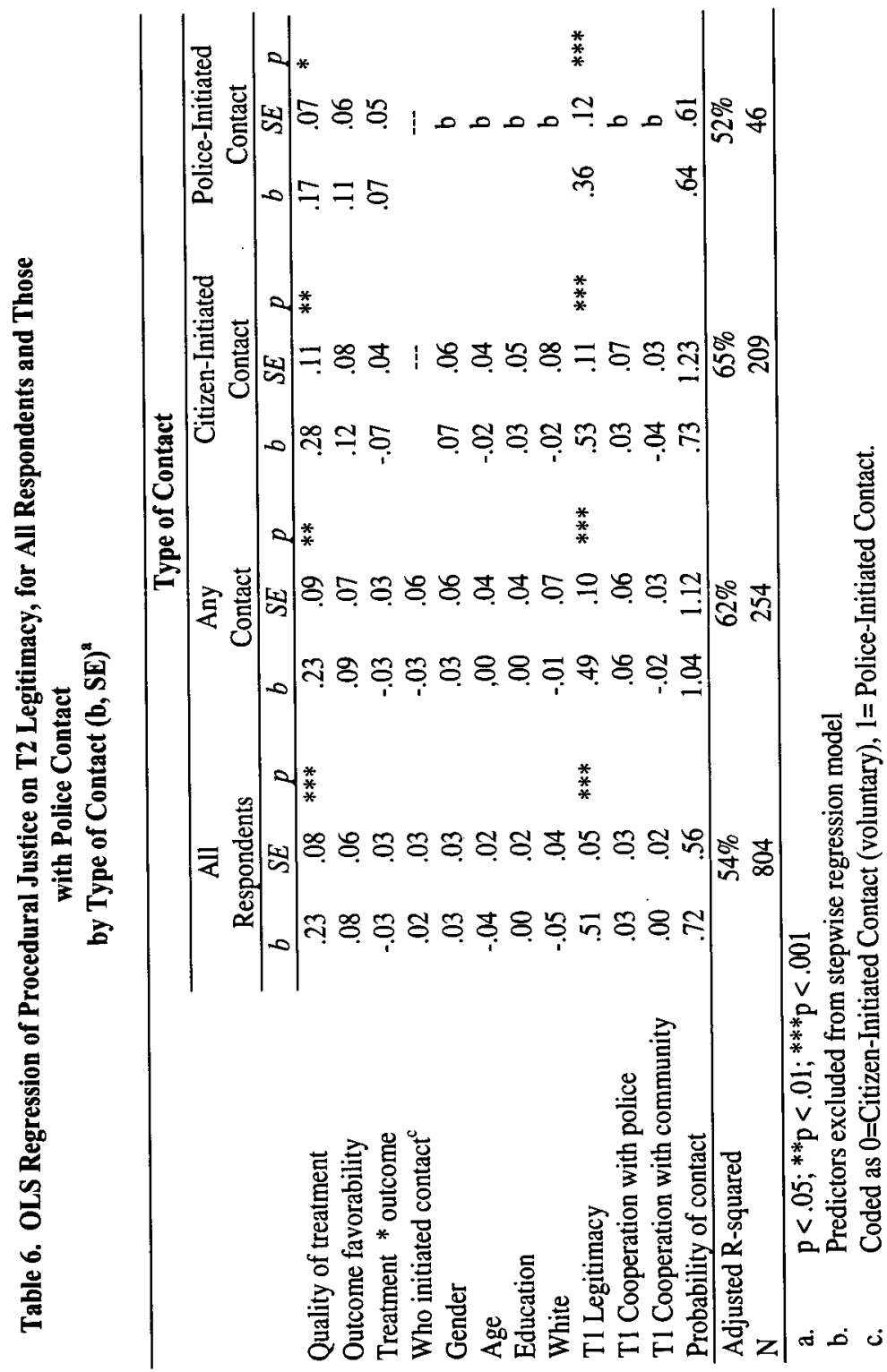


The legitimacy scale used in the analyses shown in Tables 5 and 6 contained a combination of three elements of legitimacy: obligation; trust and confidence; and identification with the police. An examination of each element indicates that those who experienced fair procedures increased their ratings of police legitimacy on each of the three aspects of legitimacy from pre-experience to post-experience. They felt greater obligation to obey $(\mathrm{t}=2.84, \mathrm{p}<.01)$; had more trust and confidence in the police $(t=4.94, \mathrm{p}<.001)$; and identified more strongly with the police $(\mathrm{t}=4.90, \mathrm{p}<.001)$.

Although the pattern reported is consistent with the argument that people became more favorable in their views following a positive experience, it is also possible that those with more favorable attitudes in the first place were more likely to personally deal with the police. We can test this possibility by comparing those who would later have personal experiences to those who would not in terms of the views they express at time one. A comparison of those who later had or did not have a personal experience in the year after the first interview indicates that the two groups did not differ in their ratings of police legitimacy at the time of the first interview $(t=1.86, n . s$.).

Consistent with the argument that experience shaped attitudes at time two, those who had had a procedurally just encounter with the police made significantly higher ratings of police legitimacy than did those people who had no encounter during the year between the two interviews $(t=3.74, p<.001)$. And those who had had a procedurally unjust encounter with the police made significantly lower ratings of police legitimacy than did those people who had no encounter with the police $(t=7.61, p<.001)$. Figure 1 illustrates the separate and distinct influences of perceived fairness on attributed legitimacy. Using a simple binary metric, we classified respondents as having had positive or negative encounters with police. The legitimacy scores were adjusted for the T1 covariates, and centered at a mean of zero. Those with positive experiences attributed greater legitimacy to the police, while those with negative experiences attributed less legitimacy to the police. While we see some evidence of asymmetry, similar to Skogan, the importance of positive experiences on attributed legitimacy is apparent and distinct from the effects of negative encounters. 


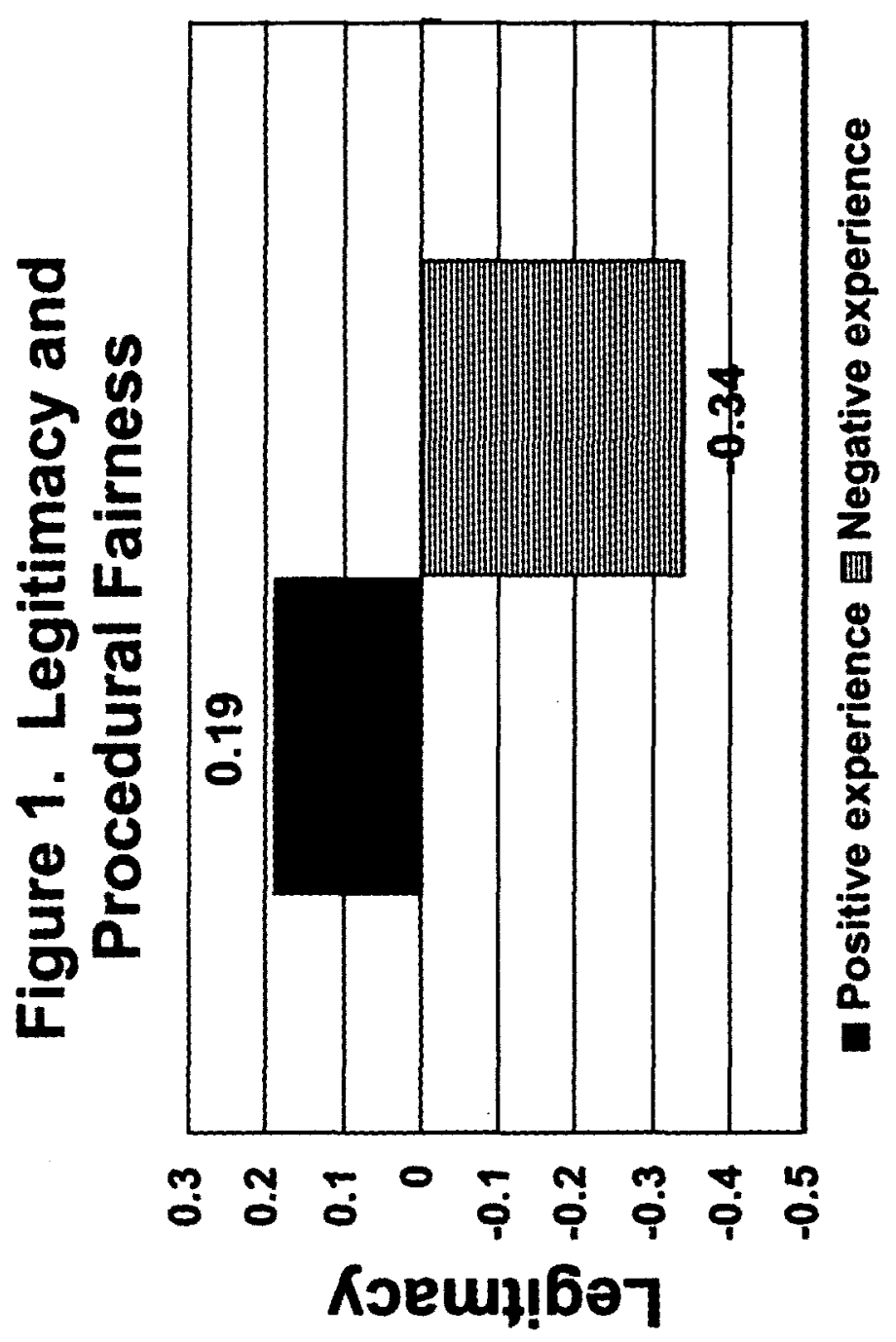


These findings suggest that, consistent with a procedure-based approach, legitimacy increases, even in the face of the delivery of negative outcomes. Those people who received a negative outcome via a just procedure increased their views about the legitimacy of the police and the law following a personal experience with a legal authority. They also suggest that differences in prior attitudes do not account for this effect. Conversely, legitimacy increased when the police delivered desirable outcomes, suggesting that the police can build support through fair treatment of the people with whom they deal.

\section{DISCUSSION}

\section{A. Why Do People Cooperate with the Police?}

The first hypothesis is that legitimacy will influence people's willingness to cooperate with the police to fight crime in their communities. The results of the analysis suggest that legitimacy shapes willingness to cooperate with the police in fighting crime. The results for working with others in the community are more mixed. Among minorities legitimacy encourages working with others, but not among Whites. In both groups people who identify with their communities are more willing to cooperate with others in their community.

As noted in the introduction, recent discussions of crime and urban disorder suggest that the police have difficulty effectively managing crime without the support of the community. ${ }^{75}$ This argument is consistent with the suggestion that the police have difficulty enforcing the law unless they can count on widespread cooperation from members of the public. ${ }^{76}$ Both arguments emphasize the point that, while society creates legal authorities and institutions to manage problems of social order, the success of those authorities is ultimately linked to the attitudes and behaviors of people living within the communities involved. The work of the authorities is more difficult, and is sometimes impossible, without the active cooperation of the people in the community.

From the perspective of the people involved, the calculus behind decisions about whether and how much to cooperate with the police and the law mirrors the tradeoffs aptly described by the dilemmas widely studied within the social sciences. In particular, it reflects the issues involved in social dilemmas. It is often in people's self-interest to ignore or disobey laws and other social regulations, and to avoid helping the police by identifying criminals or engaging in community crime-prevention activities, since the latter behavior carries risks and has an uncertain positive payoff. On the other hand, if wrongdoing becomes widespread and the community generally fails to help the police to manage social order, everyone in the community suffers directly or indirectly. Hence, the mixed motive dynamics of the social dilemma-everyone would prefer not to help the 
community but have their neighbors do so-a view that, if widely acted on, leads to disorder and decline.

Typical approaches to resolving the social dilemma problem have been instrumental. They are based upon the belief that if the risks of rule breaking or the gains of cooperating with the police are increased people's self-interest calculus changes. And, as research makes clear, so does their behavior. We know that people are less likely to break the law if the risk of doing so is greater, just as they are more likely to act to help their community when the gains of cooperation are more certain. ${ }^{7}$ The findings of this study confirm these instrumental influences by demonstrating that people are more cooperative with the police when they believe that police performance in fighting crime is more effective and that the police create a credible threat of punishment for wrongdoing.

While the potential value of instrumental approaches is clear, so are some of their limits. One limit is that, when they do influence behavior, the influence of instrumental calculations on behavior is, at best, small. Second, these strategies are most effective against instrumental crimes such as burglary and car theft, and in situations where surveillance is possible. Finally, even when they are effective, instrumental strategies are costly to implement, making them difficult to use during times of crisis, or in communities with limited resources.

Recognizing the limits of instrumental approaches, it has been argued that there are important advantages associated with self-regulatory models of order maintenance. ${ }^{78}$ These models have the advantage of being based on people's own internal values, values that motivate behavior distinctly from the motivating influence of incentives and sanctions. To the degree that people are motivated by their values, they cooperate because they believe it is appropriate and proper, not because they believe it is in their immediate self-interest. One important value is legitimacy.

The value of a legitimacy based approach rests on the finding that appeals to legitimacy shape people's behavior. The findings outlined here show that they can. They demonstrate that people are more willing to cooperate with the police when they view the police as legitimate social authorities. If people view the police as more legitimate, they are more likely to report crimes in their neighborhood. In addition, minority group members are more likely to work with neighborhood groups.

77 Nagin, supra note 4.

78 TYLER \& HUO, supra note 16; Tom R. Tyler, Promoting Employee Policy Adherence and Rule Following in Work Settings: The Value of Self-Regulatory Approaches, 70 BROOK. L. REV. 1287 (2005); Tom R. Tyler \& Steven L. Blader, Can Businesses Effectively Regulate Employee Conduct? The Antecedents of Rule Following in Work Settings, 48 ACAD. MGMT. J. 1143 (2005); Tyler \& Darley, supra note 19. 


\section{B. How Is Legitimacy Created And Maintained?: The Role of Procedural Justice}

How can legitimacy be created and maintained? The second hypothesis is that procedural justice will be the central antecedent of legitimacy. The findings support this suggestion, and point to the justice of police policies and practices as key factors shaping police legitimacy. As is hypothesized based upon the psychological literature on procedural justice, people evaluate the legitimacy of the police largely in terms of their judgments about the fairness by which the police exercise their authority. ${ }^{79}$ This does not mean that performance assessments are irrelevant-they are not. One factor shaping legitimacy is performance. However, once performance has been taken into account, legitimacy judgments are still shaped by procedural justice assessments.

In the past several decades those concerned with policing have focused on efforts to improve the objective quality of policing by developing better strategies for police efforts to fight crime, as well as improving the accountability of the police to the community for corruption, harassment and abuse of authority. These efforts have lead to marked improvements in the objective quality of policing in the United States. ${ }^{80}$ Despite these increases in the quality of policing, the police continue to have difficulty securing public cooperation, especially among minority group members, and in some cities police-community relations continue to be characterized by hostility and antagonism. These findings point to an alternative path to cooperation. This approach focuses on developing and maintaining the legitimacy of the police in the eyes of the public as another way that the police can by effective in fighting crime and urban disorder.

The findings of this study point directly to the value of process-based policing. ${ }^{81}$ In a strategy of process-based policing the police strive to exercise their authority in ways that members of the public evaluate as fair. Such a strategy is not, of course, confined to policing. Similar arguments apply to the courts, ${ }^{82}$ to government, ${ }^{83}$ and to the management of for-profit organizations. ${ }^{84}$ Research suggests that irrespective of context, legitimacy is strongly shaped by the procedural justice by which relevant authorities exercise their authority. These findings point to the value to the legal system of an empirically oriented analysis of the meaning of procedural justice. Knowing what is experienced by members of the public as fair or unfair is key to developing and maintaining public views that the legal system is legitimate.

79 TYLER, Why PEOPLe OBEY, supra note 1; TYLER \& HuO, supra note 16.

80 FAIRNESS AND EFFECTIVENESS IN POLICING, supra note 8.

81 See TYLER \& HUO, supra note 16.

82 Id. See also Tyler, Public Trust, supra note 63.

83 Tom R. Tyler, A Psychological Perspective on the Legitimacy of Institutions and Authorities, in THE Psychology OF LegrTIMACY 416 (John T. Jost \& Brenda Major eds., 2001).

Tyler, Procedural Justice, supra note 39. 
While this study examines views about the police among the general public, it should be noted that the same findings about the importance of procedural justice emerge in studies in which the type of cooperation studied is deference to particular decisions during personal encounters with authorities. ${ }^{85}$ These findings are confirmed among the subset of respondents in this study with their personal experience with the police. The findings of an analysis among that group indicate that legitimacy increases following personal experience with the police among both those with favorable and unfavorable outcomes, as long as those involved feel that the procedures used by the police were fair.

An example of the policy implications of these findings is found in recent research on racial profiling. ${ }^{86}$ Thinking that one has been stopped by the police because of one's ethnicity reflects the belief that one has been profiled. This judgment has negative consequences during personal encounters with the police, because it encourages resistance and antagonism, as well as undermining the legitimacy of the police. On the community level, if members of the community believe that profiling is widespread, they are less supportive of the police. ${ }^{87}$ These profiling effects emerge because people view profiling as an unfair policing procedure. Hence, procedural injustice leads to lowered legitimacy and diminished cooperation with the police. Conversely, if the police are procedurally fair when they deal with people, people are less likely to feel that they were profiled, and if people believe that the police are generally fair, they are less likely to think that profiling occurs. Hence, procedural justice provides a framework for understanding how people's views about police practices map onto police legitimacy and cooperation with the police.

\section{Strengths and Weaknesses of This Study}

The strength of the findings reported here flow from the fact that the data is panel data, which is a better type of correlational dataset for inferring causal relations than is cross-sectional data. In particular, a panel design allows for exogenous influences to be controlled. We have sharpened the distinction between fair treatment and fair outcome to assess their mutual influence that other studies blur or collapse. Additionally, our measures of legitimacy and cooperation are linked temporally to respondents' interactions with police, in effect allowing for the estimate of the effects of police contact as an intervention in citizens' everyday lives.

85 See TYLER \& HUO, supra note 16.

86 Tom R. Tyler \& Cheryl J. Wakslak, Profiling and Police Legitimacy: Procedural Justice, Attributions of Motive, and the Acceptance of Police Authority, 42 CRIMINOLOGY 253 (2004).

87 Id. Tyler and Wakslak's study looks at the judgments of members of the community about the frequency of profiling. Their results indicate that when people think that profiling is more widespread in the community, they are less supportive of the police and less willing to cooperate with them in fighting crime. 
At the same time, our measures of public behavior rely on self-reports, whose vulnerability to bias and measurement error suggest caution. For example, we ask respondents to estimate how frequently they comply with the law and whether they cooperate with the police. There are obvious reasons that people might not accurately self-report their law related behavior. While there are reasons to believe that self-report data is reasonable in this context, it is important to acknowledge that its use is one weakness of this study. ${ }^{88}$ Fortunately, more recent research using police records to index behavior supports the linkage of procedural justice to compliance through legitimacy. ${ }^{89}$

As in much survey research, our scenarios about cooperation are hypothetical. Because situations vary, respondents could not be asked if they had engaged in behavior. Instead, they were asked whether, if the situation arose, they would cooperate. For example, "If there were a criminal in your neighborhood, would you report them?" or "If the police held a community meeting, would you attend?" While made necessary by the situation, this hypothetical form is a weakness of the approach used in this situation. Nevertheless, research by social psychologists on behavioral intention or reasoned action suggests that predictions of future behaviors in survey research are sufficiently accurate to lend confidence to our conclusions. $^{90}$

\section{CONCLUSION}

For the police to be successful in controlling crime and maintaining social order, they must have active public cooperation, not simply political support and

88 The case of the reasonableness of self-report data about rule following is made in detail in TYLER, Why PEOPLE OBEY, supra note 1, at 40-56. That discussion notes that research comparing the findings of self-report studies and studies that use actual criminal behavior as the dependent variable yield similar findings about the reasons for rule following.

89 Tom R. Tyler, Lawrence Sherman, Heather Strang, Geoffrey C. Barnes \& Daniel Woods, Reintegrative Shaming, Procedural Justice, and Recidivism: The Engagement of Offenders' Psychological Mechanisms in the Canberra RISE Drinking-and-Driving Experiment, 41 L.\& SoC'Y REV. 553 (2007).

90 Studies by social psychologists indicate that people's intentions to act in particular ways (e.g., "I will report criminals if I see them") are consistently found to be strong predictors of their actual behavior. See Icek Ajzen, From Intentions To Actions: A Theory Of Planned Behavior, in ACTION CONTROL: From COGNTION TO BEHAvior 11, 21 (Julius Kuhl \& Jurgen Beckmann eds., 1985) (demonstrating that intention is the strongest predictor of human behavior, where intention is an immediate antecedent of behavior, activated by a cognitive representation of readiness to perform the behavior). See also ICEK AJZEN \& MARTIN FishBein, UNDERSTANDING ATTTTUDES AND Predicting Social Behavior 54-60 (1980) (showing that a person's behavior is determined by his/her intention to perform the behavior and that this intention is, in tum, a function of his/her attitude toward the behavior and his/her subjective norm); Blair H. Sheppard, Jon Hartwick \& Paul R. Warshaw, The Theory of Reasoned Action: A Meta-Analysis of Past Research with Recommendations for Modifications and Future Research, 15 J. CONSUMER RES. 325 (1988). 
approval. Cooperation increases not only when the public views the police as effective in controlling crime and maintaining social order, but also when citizens see the police as legitimate authorities who are entitled to be obeyed. Such legitimacy judgments, in turn, are shaped by public views about procedural justice-the fairness of the processes the police use when dealing with members of the public. These findings demonstrate the value to the police of having public legitimacy and indicate how such legitimacy can be sustained. 


\section{APPENDIX A: \\ METHOD}

The Wave 1 sample $(n=1,653)$ was racially and ethnically diverse: $34 \%$ White, 25\% Hispanic; 28\% African-American; and 13\% other Non-White. Data from the 2000 Census show that New York City's adult population at the time of the survey was $35 \%$ Non-Hispanic White, $27.0 \%$ Hispanic, $24.5 \%$ African American, and $13.5 \%$ Other Non-White and Non-Hispanic. ${ }^{91}$ Accordingly, the Wave 1 sample closely approximated the racial and ethnic composition of the City.

This diversity was maintained among those who were reinterviewed during the second time of the study $(\mathrm{n}=879)$. In the time two sample $38 \%$ were white; $22 \%$ were Hispanic; $28 \%$ African-American; and $11 \%$ other non-White. In addition, the Wave 1 and Wave 2 samples were closely matched on gender, age, education, and income. These demographics are outlined in the table below.

Interviews were conducted by telephone, and lasted no more than 25-30 minutes. Respondents gave informed consent verbally prior to beginning the interview. Responses were recorded by interviewers directly into a database using pre-programmed response screens.

91 See Population division, New York City Dep't of City Planning, Demographic PROFILE 1990-2000, available at $\mathrm{http}: / / \mathrm{www} . n y c . g o v / \mathrm{html} / \mathrm{dcp} / \mathrm{html} / \mathrm{census} / \mathrm{demo}$ _profile.shtml. 
TABLE A1. SAMPLE DEMOGRAPHICS

Age

$18-24$

25-34

$35-54$

$55-64$

$65+$

Education

Less than HS

HS graduate

Some college

College graduate

Graduate work

Income

Under $\$ 20,000$

$\$ 20,000-\$ 29,999$

$\$ 20,000-\$ 29,999$

$\$ 20,000-\$ 29,999$

$\$ 50,000-\$ 74,999$

$\$ 75,000-\$ 99,999$

$\$ 100,000+$

Race

Hispanic

African-American

White

Other nonwhite

Gender

Male
T1

$14.0 \%$

26.4

38.2

9.9

11.5

$\mathrm{T} 1$

$12.4 \%$

22.7

20.5

31.4

13.0

T1

$17.8 \%$

15.8

12.7

11.8

17.5

10.0

14.4

T1

$25.2 \%$

28.0

33.8

12.9

T1

$46.2 \%$
T2

$11.2 \%$

22.3

38.9

12.7

15.0

T2

$11.8 \%$

21.8

21.4

31.6

13.4

T2

$17.7 \%$

14.1

13.5

12.5

18.0

11.1

13.2

T2

$22.2 \%$

28.2

38.2

11.4

T2

$44.2 \%$ 


\section{ITEMS AND MEASURES}

\section{Cooperative Behavior}

Two dimensions of cooperation were assessed: assisting the police in crime prevention and criminal investigations, and complying with the law. Assistance was assessed by asking respondents, if the situation arose, how likely they would be to: (a) call the police to report a crime; (b) help the police to find someone suspected of a crime; (c) report dangerous or suspicious activity; (d) volunteer time to help the police; (e) patrol the streets as part of an organized group; and (e) volunteer to attend community meetings to discuss crime. The response scale was: (4) very likely; somewhat likely; not too likely; and not likely at all (1).

For compliance, respondents were asked how frequently they followed rules concerning: (a) where they could legally park their car; (b) how to dispose of trash and litter; (c) making too much noise at night; (d) speeding or breaking other traffic laws; (e) buying possibly stolen items on the street; (f) not taking inexpensive items from stores; $(\mathrm{g})$ using illegal drugs such as marijuana. The response scale was: (5) all of the time; almost all of the time; most of the time; some of the time; or none of the time (1).

Based upon the results of a principle components factor analysis with varimax rotation, four scales were created using the factor scores. Because of the small number of items within each of the four scales, Chronbachs alphas were only moderately high, within the $0.60-0.80$ range, which is acceptable. The Wave 1 means and standard deviations for each scale are shown in Table A1.

\section{Attitudes About the Police}

Legitimacy. The legitimacy of the police was assessed by asking about three issues: obligation; trust and confidence; and identification with the police. Obligation and trust and confidence measures were drawn from Tyler, while identification with the police was assessed following the approach of Tyler and Huo. ${ }^{92}$

Respondents were first asked whether or not they felt that they ought to obey the police in situations in which the police told them how to behave and/or when there were relevant laws. The scale included ten items, ranging from high (5) to low (1). The items were; "Overall, the NYPD is a legitimate authority and people should obey the decisions that NYPD police officers make"; "You should accept the decisions made by police, even if you think they are wrong?"; "You should do what the police tell you to do even when you don't understand the reasons for their

92 This study was based on survey responses from residents of Oakland and Los Angeles who were asked questions about recent personal experiences with the police and the courts. The questions used had fixed response alternatives. The particular items used are included in the appendix and were generally drawn from this prior research. For details, see TYLER AND HUO, supra note 16. 
decisions?"; "You should do what the police tell you to do even when you disagree with their decisions"; "You should do what the police tell you to do even when you don't like the way they treat you?"; "There are times it is ok for you to ignore what the police tell you to do (reverse scored)"; "Sometimes you have to bend the law for things to come out right (reverse scored)"; "The law represents the values of the people in power, rather than the values of people like you (reverse scored)"; "People in power use the law to try to control people like you (reverse scored)"; and "The law does not protect your interests (reverse scored)."

In addition, respondents were asked whether or not they had trust in the police as an institution. The scale used seven items, ranging from high (5) to low (1). The items were: "I have confidence that the NYPD can do its job well"; "I trust the leaders of the NYPD to make decisions that are good for everyone in the city"; "People's basic rights are well protected by the police"; "The police care about the well-being of everyone they deal with"; "The police are often dishonest (reverse scored)"; "Some of the things the police do embarrass our city (reverse scored)"; and "There are many things about the NYPD and its policies that need to be changed (reverse scored)."

Finally, they were asked whether they identified with police officers, i.e., generally sharing their values and respecting them as people. The scale included ten items, ranging from high (5) to low (1). The items were: "If you talked to most of the police officers who work in your neighborhood, you would find they have similar views to your own on many issues"; "Your background is similar to that of many of the police officers who work in your neighborhood"; "You can usually understand why the police who work in your neighborhood are acting as they are in a particular situation"; "You generally like the police officers who work in your neighborhood"; "If most of the police officers who work in your neighborhood knew you, they would respect your values"; "Most of the police officers who work in your neighborhood would value what you contribute to your neighborhood"; "Most of the police officers who work in your neighborhood would approve of how you live your life"; "I am proud of the work of the NYPD"; "I agree with many of the values that define what the NYPD stands for."

\section{Police Performance}

Police performance was first measured via estimates of the likelihood that a rule breaker would be caught and punished for rule breaking; fear of crime; and judgments about neighborhood crime conditions.

Sanction risk. To determine the degree to which respondents felt that the police created an effective deterrent to rule breaking, they were asked how likely they thought it was that they would be caught and punished if they broke each of the seven laws used to determine cooperation. Seven items were used, ranging from (5) high to (1) low.

Crime concerns. Crime concerns were assessed in two ways: fear of crime and estimates of crime. To determine fear of crime respondents were asked a 
series of questions about how well the police managed crime in the respondent's neighborhood (three items, ranging from (4) high to (1) low. To evaluate neighborhood conditions respondents were asked about the existence of conditions such as "graffiti on neighborhood walls" and "empty beer bottles on the streets or sidewalks", as well as two questions about the rate of crime in the neighborhood (using eight items, ranging from (4) high to (1) low.

\section{Identification with One's Neighborhood}

In addition to measuring respondent judgments about the police, the degree to which respondents identified with their neighborhood was also assessed. Drawing upon the psychological literature on cooperation, which links cooperation to identification with a group, ${ }^{93}$ identification with neighborhood was assessed using a seven item scale, ranging from (4) high to (1) low. The items were: "How important is the neighborhood in which you live to the way that you think of yourself as a person?"; "You are proud to live in your neighborhood"; "Things that people in your neighborhood stand for are important to you"; "When someone praises the achievements of others in your neighborhood, it feels like a personal compliment to you"; "Most of the people in your neighborhood respect your values"; "Most of the people in your neighborhood value what you contribute to the neighborhood"; and "Most of the people in your neighborhood approve of how you live your life."

\section{Evaluations of Police Actions}

Based upon procedural justice theory, two distinct aspects of procedural justice were measured: the justice of decision making and the justice of interpersonal treatment. These assessments were asked for both global evaluations of police, and actions of police in the respondent's personal experience. This model reflects the findings of research in work settings. ${ }^{94}$

Justice of police decision making. The fairness of police decision making was assessed using five items, ranging from (5) agree strongly to (1) disagree strongly. The items were: "Usually accurately understand and apply the law"; "Make their decisions based on facts, not their personal biases and opinions"; "Try to get the facts in a situation before deciding how to act"; "Give honest explanations for their actions to the people they deal with"; "Apply the rules consistently to different people."

Justice of police interpersonal treatment. The justice of police treatment of residents of the community was assessed using four items, ranging from (5) agree strongly to (1) disagree strongly. The items were: "Treat people with dignity and 
respect"; "Respect people's rights"; "Consider the views of people involved"; and "Take account of the needs and concerns of the people they deal with."

Police distributive fairness to the respondent. Respondents were asked about the fairness of the delivery of police services to people like themselves. The scale ranges from (4) fair to (1) unfair.

\section{Judgments about Personal Experience with the Police}

Next, those respondents who reported personal experience were asked a set of questions about that personal experience.

Justice of police decision making during personal experience. The justice of police decision making was assessed using six items, each with a four item response scale ranging from agree strongly (4) to disagree strongly (1). The items were: "Decisions about what to do were made fairly"; "I had the opportunity to describe my situation before decisions were made"; "I was treated the same way that others would be treated in a similar situation"; "The police made their decision based on facts"; "I received the same outcome that others would receive in the same situation"; and "My race/ethnicity did not influence how I was treated by the police."

Justice of police interpersonal treatment during personal experience. The justice of police interpersonal treatment was determined using six items, each with a four point response scale ranging from (4) agree strongly to (1) disagree strongly. The items were: "The police were honest in what they said to me"; "The police tried hard to do the right thing"; "The police tried to take my needs into account"; "The police cared about my concerns"; "The police treated me politely"; "The police respected my rights."

Fairness of the outcomes during personal experience. The fairness of the outcome during the personal experience was assessed using three items, each with a four point response scale ranging from (4) agree strongly to (1) disagree strongly (mean $=3.97$; s.d. $=1.14$; alpha $=0.94)$. The items were "I received a fair outcome"; "I received the outcome I deserved according to the law"; and "I received the outcome I feel I deserved."

Favorability of outcomes during personal experience. Three items were used, with a four point response scale ranging from (4) agree strongly to (1) disagree strongly. They were: "Overall, how satisfied were you with how the officer(s) handled your situation"; "How satisfied were you with the outcome of your experience"; and "From your perspective, was the outcome very good, somewhat good, somewhat bad, or very bad for you?"

The willingness to accept decisions following personal experience. A two item scale measured willingness to accept police decisions, with each item using a four point response scale ranging from (4) agree strongly to (1) disagree strongly. The items were: "I willingly accepted the decisions the police made"; and "In a similar situation in the future, I would like to see the situation handled in the same way." 
Motivation to complain. Two items assessed motivation to question the decision, with each item using a four point response scale ranging from (4) agree strongly to (1) disagree strongly. "I considered going to others to complain about the actions of the police"; "I considered going to others to try to change the decisions the police made." 
APPENDIX A2. SCALE PROPERTIES

\begin{tabular}{|c|c|c|c|}
\hline & Mean & $\begin{array}{l}\text { Standard } \\
\text { Deviation }\end{array}$ & $\alpha$ \\
\hline \multicolumn{4}{|l|}{ Compliance and Assistance } \\
\hline Compliance with Minor Laws & 3.40 & 0.73 & \\
\hline Compliance with Major Laws & 3.63 & 0.88 & \\
\hline Helping the Police & 2.57 & 0.60 & \\
\hline Helping Neighbors & 1.78 & 0.85 & \\
\hline \multicolumn{4}{|l|}{ Legal Orientation $^{I}$} \\
\hline Legitimacy & 3.62 & 0.58 & 0.61 \\
\hline Trust in Police & 3.56 & 0.62 & 0.82 \\
\hline Attitudes Toward Police & 3.96 & 0.69 & 0.87 \\
\hline Sanction Risk & 3.54 & 0.96 & 0.87 \\
\hline \multicolumn{4}{|l|}{ Perceptions of Neighborhood and Crime } \\
\hline Crime Problems in Neighborhood & 2.76 & 0.67 & 0.73 \\
\hline Physical Disorder & 2.04 & 0.67 & 0.82 \\
\hline Neighborhood Identification & 1.78 & 0.60 & 0.77 \\
\hline \multicolumn{4}{|l|}{ Procedural Justice-General } \\
\hline Fair Decisions & 3.67 & 1.07 & 0.85 \\
\hline Respectful Treatment & 3.82 & 0.99 & 0.83 \\
\hline Outcome Favorability & 2.16 & 1.46 & \\
\hline \multicolumn{4}{|l|}{ Procedural Justice Personal Experience ${ }^{2}$} \\
\hline Fair Decisions & 3.27 & 0.76 & 0.76 \\
\hline Respectful Treatment & 3.22 & 0.96 & 0.94 \\
\hline Outcome Favorability & 2.97 & 1.05 & 0.90 \\
\hline Willingness to Accept Police Decision & 3.07 & 1.08 & 0.79 \\
\hline Motivation to Complain & 3.36 & 0.97 & 0.80 \\
\hline
\end{tabular}

1. All of the reliabilities reported for the Legal Orientation measures were computed on the T1 sample.

2. All of the reliabilities reported for Personal Experience were computed on the T1 sample. 
